\title{
Parametric Study of Light-Well Design for Day-Lighting Analysis under Clear Skies
}

\author{
Bakr M. Aly Ahmed, Khaled M. Nassar, and Adnan Asr
}

\begin{abstract}
Lightwells are vertical spaces used in multistory buildings to illuminate spaces without direct day light access. In many countries the building code allows for kitchen and bathroom to be mechanically ventilated and lighted, while in other countries and jurisdictions, building codes necessitate that such spaces be naturally ventilated and lighted. Therefore, lightwells become an integral part of the design especially in sites with min frontage and multistory residential buildings. Design requirement based solely on the dimensions and area neglects several aspects that may affect the performance of the lightwell. Reflectivity, windows area and aspect ratio, building orientation, and the aspect ratio of the light-well itself are important factors in determining the performance. In order to assess and develop rational criteria for lightwell design, this study aims at conducting a parametric study to assess the effectiveness of light well design. Two famous lightwell index formulae are calculated and correlated to the day light performance. Various measures were used to test the day light performance including dynamic "climate based" measures. RADIANCE simulation models and an automated process using LUA code were used to perform the parametric variations. A physical building model was used to calibrate the RADIANCE simulation. This study will be of interest to building officials setting code requirements as well as practicing architects.
\end{abstract}

Index Terms-Daylight index, lightwell, parametric study, RADIANCE.

\section{INTRODUCTION}

Lightwells are very common in many countries, especially those, such as Egypt, that require natural ventilation and lighting for bathrooms and kitchen spaces.

The limits set on the lightwell design based on the building code in Egypt are questionable. In this case, building codes prescribe minimum areas and dimensions for the light well design. These minimum area and dimension values are usually set as a function of the building and lightwell height. Table I shows the minimum requirements by the Egyptian codes for interior and exterior lightwell dimensions.

It is questionable, How such values are set? And the arbitrary and empirical nature that these values are defined?

Furthermore, setting design requirement based solely on dimensions and area neglects several aspects that may affect the performance of the lightwell in terms of both ventilation and lighting. For the lighting performance of the lightwell for

Manuscript received May 7, 2013; revised July 24, 2013.

Bakr M. Aly Ahmed is with Department of Architecture, North Dakota State University, 650 NP Ave, Fargo, ND 58102, tele: 701-231-5901 (e-mail: bakr.alyahmed@ndsu.edu).

Khaled M. Nassar and Adnan Asr are with Department of Construction and Architectural Engineering, American University in Cairo, Office: SSE 1139, (tele: 2615.2630; e-mail knassar@ aucegypt.edu). example, the reflectivity, the window area and aspect ratio, the building orientation and the aspect ratio of the light well itself are important factors in determining the performance.

TABLE I: SHOWS LIMITS SET ON THE LIGHT WELL DESIGN BASED ON THE BUILDING CODE IN EGYPT. [1]

\begin{tabular}{|c|c|c|c|}
\hline Space Function & Light well type & Min Dimension & Min Area \\
\hline Residential rooms \& offices & interior or exterior & $\begin{array}{c}0.25 \text { of building } \\
\text { height or } 3 \mathrm{~m}\end{array}$ & $(1 / 3 h) 2$ \\
\hline \multirow{5}{*}{ kitchens \& bathrooms } & $\begin{array}{l}\text { exterior light } \\
\text { pocket }\end{array}$ & $2.5 \mathrm{~m}$ & $h=10 \mathrm{~m}, 7.5 \mathrm{~m} 2$ \\
\hline & \multirow{4}{*}{ interior light well } & \multirow{4}{*}{$2.5 \mathrm{~m}$} & $h=20 \mathrm{~m}, 10 \mathrm{~m} 2$ \\
\hline & & & $\mathrm{h}=30 \mathrm{~m}, 12.5 \mathrm{~m} 2$ \\
\hline & & & $2.5 \mathrm{~m} 2$ for each $10 \mathrm{~m}$ \\
\hline & & & increase in height \\
\hline
\end{tabular}

The design of lightwell lends itself to a parametric study since firstly, the design parameters affecting the lightwell are relatively limited, secondly, the lightwell has limited impact on the overall building design and concept and therefore can be designed and optimized within the framework of the entire building design, and thirdly, few exogenous variables affect the lightwell performance [2].

Previous research on the topic has demonstrated that the longer and narrower a lightwell is, the less efficient it becomes; the larger and wider it is, the larger illuminance it provides [3]. Kristl and Krainer examined the performance of a lightwell for a three-story model building with its inner surfaces painted with matt white. They carried out measurements and analysis on the scale model of an energy conscious multi-story apartment building using light wells as an additional source of daylight [4]. In addition to daylighting, a lightwell may facilitate natural ventilation to improve the thermal performance of a high-rise building if its duct structure can be appropriately designed to permit natural ventilation [5], [6]. When applying a lightwell to a building, the regional climate as well as the functional characteristics of the building should be considered besides its physical dimensions and properties to produce the optimum daylighting performance. Recently, Su et al have studied the light well design. Their research has also shown RADIANCE simulation has a good agreement with the measurement for the case with no cover on the light-well top opening [7].

\section{CODE ANALYSIS FOR LIGHTWELLS AND COURTS}

Although the International Building Code (IBC) specifies that all habitable spaces to have natural or artificial light, in some jurisdictions, natural light is required for all space (even 
bathrooms and kitchens). Artificial light is to be provided at a 10 foot-candle (107 lux) over the area of the room at a height of 30 inches $(762 \mathrm{~mm})$. There is no specific light-quantity requirement set for natural light. This means that in theory, there could be a building that is occupied only during daylight hours that does not have any artificial lighting but instead gets all its light naturally. Note also that the code allows interior rooms to borrow light from adjacent rooms if at least half of the wall between them is open and the opening must be at least the larger of $10 \%$ of the floor area of the interior room or 25 squared-feet (2.3 squared-meters).

Exterior openings are to open to the outdoors, to yards and to courts. Codes set minimum sizes for the light wells and yards of multistory buildings in order to insure a minimum amount of natural light and ventilation into the building spaces that they serve.

Yards can be considered as areas between the proposed building and the any adjacent buildings and therefore function similar to light wells. If yards are open to a public way or another yard then they function similar to a light pocket. Yards are to be at least 3 feet $(914 \mathrm{~mm})$ wide for the first two stories. The width of the yards must increase by 1 foot for every floor above the second floor. This increase applies up to 14 stories and building exceeding fourteen stories need not have a yard greater than 15 foot $(4572 \mathrm{~mm})$ wide.

In the case of a light well where windows face each other the minimum court width is to be 6 feet $(1829 \mathrm{~mm})$. The court can be stepped up or the court walls may be vertical is the court size is as determined by the largest court dimension required at the top story.

Courts must be at least 10 feet $(3048 \mathrm{~mm})$ in length unless bounded on one end by a public way or yard, in which case they are considered light pockets. Courts also must be at least 3 feet $(914 \mathrm{~mm})$ in width for buildings up to two stories tall.

Courts must increase 1 foot $(305 \mathrm{~mm})$ in width and 2 feet $(610 \mathrm{~mm})$ in depth for every floor above the second floor up to a limit of 14 stories, beyond which increases are not required. Thus a court for a 14-story building with windows facing each other would be at least 15 feet by 34 feet ( 4572 $\mathrm{mm}$ by $10363 \mathrm{~mm}$ ).

\section{EXPERIMENTAL DESIGN}

Ecotect by itself cannot be used. The differences can be attributed to the fact that the ECOTECT split-flux method does not take multiple lighting reflectance into account which leads to a gross under-prediction of interior lighting levels in the presence of thick walls, light-shelves, overhangs or other elements that are commonly found in daylight spaces.

In clear sky conditions the position of the sun in the sky is an important factor. Therefore any parametric study of the light pocket should consider orientation, the day and time as well as other design factors. Therefore we considered calculating some dynamic daylighting performance measures as summarized in such as daylight autonomy, useful daylight illuminance, continuous daylight autonomy, annual light exposure, Several studies have demonstrated that the Radiance ray tracer combined with a daylight coefficient approach and the Perez Sky Model is able to reliably and effectively calculate time series of illuminance and luminance in buildings [8]-[10]. An overview of the daylight coefficient approach and selected Radiance validation studies can be found under Reinhart and Anderson [9]. Therefore in order to conduct the parametric study under the clear sky conditions, there were at least 2 different methods that could be used. Firstly, a set of daylight coefficients can be calculated for each of the points in a sensor point grid and then combine these daylight coefficients with climate data to yield the annual time series of interior illuminance and luminance. This process could be fully automated using a number of software such as Daysim, ESP-r, or Lightswitch wizard, however calculating dynamic simulation measures will take a longer processing time [8]. The second method would be to conduct a full ray tracing calculation at different points of time for each grid sensor point. This obviously would take even more calculation time but would result in more accurate results. Add to this the fact that in a parametric study a large number of simulations are needed for each parametric variation of the original model.

Although light wells and light pockets are used differently in many buildings, the basic configuration remains the same. Properly applied, daylighting does not allow the sun to directly enter a space. Top lighting and side lighting are the two primary daylighting design strategies. Top lighting involves letting light in through glazed openings in the roof, such as clerestories, skylights, atria, and monitors, and is usually limited to the top floor of a building. Top lighting openings are often provided with shades, blinds, and other forms of light-blocking devices for times when daylight is too bright for the functions to be performed in the space. Side lighting involves admitting light through windows and courtyards. Light shelves are devices that direct reflected daylight farther into a space than would occur just from the light entering the window. The light shelf sits above the view windows and throws daylight off a highly reflective ceiling so that occupants in the space away from windows can benefit from daylight. Side lighting can be applied to multiple floors of a building with the correct exposure and orientation. Light shelves can be either exterior or interior mounted or may be a combination of both. Note that in spaces where the suspended acoustical ceiling is eliminated in favor of a higher, brighter hard ceiling, acoustical problems can result from the lack of sound-absorbing material in the space. Typically, exterior light shelves are not considered for buildings in parts of the country that have heavy snowfall.

\section{MethodolOGY}

The model for the lightwell was $4000 \mathrm{~mm}$ (width) $\times$ $4000 \mathrm{~mm}$ (length) $\times 14000 \mathrm{~mm}$ (height) and placed in an envelope of $12000 \mathrm{~mm} \times 12000 \mathrm{~mm} \times 14000 \mathrm{~mm}$ that was divided into five floors. The lightwell has four windows in each floor. Each floor was partitioned into eight equal spaces. The model window was $1000 \mathrm{~mm} \times 1000 \mathrm{~mm}$. Fig. 1 gives the picture of the model lightwell and its perspective view using Autodesk ${ }^{\circledR}$ Ecotect ${ }^{\mathrm{TM}}$ Analysis tool. RADIANCE is a well-known, lighting simulation program used to investigate various physical elements that affect the visual environment. 
RADIANCE is capable of producing high quality rendered image of an object and carries out lighting analysis in an accurate way.

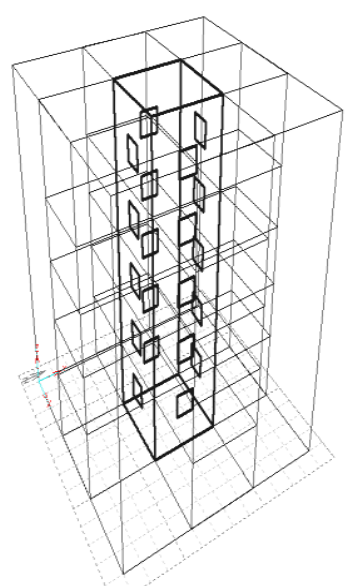

Fig. 1. Five-floor building model with a lightwell

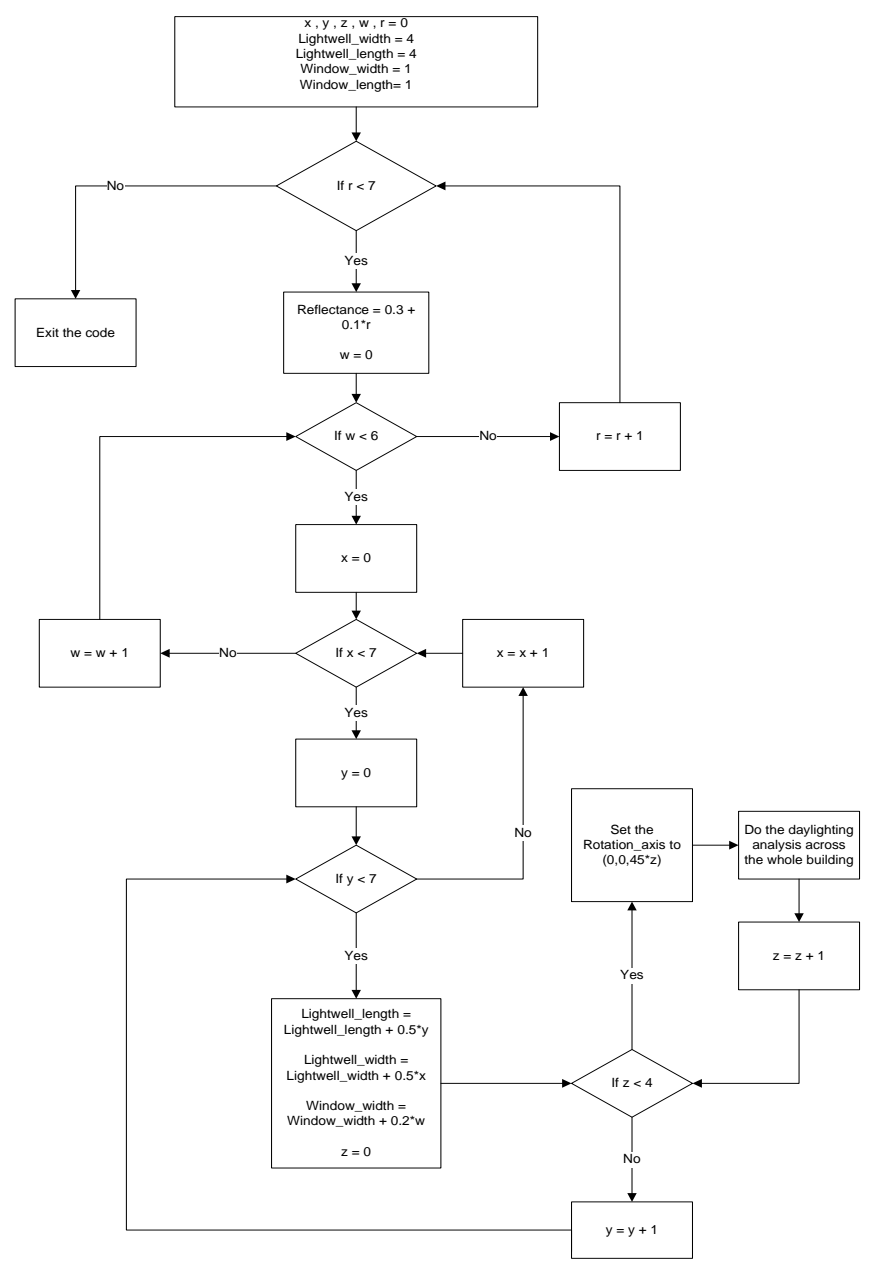

Fig. 2. Flow chart showing the algorithm used for the daylighting analysis.

RADIANCE simulation of the model lightwell was carried out to investigate the daylighting analysis of the lightwell. Due to the extensive simulation time required, parallel processing of the simulation was conducted on multiple Quad dual core processor computers. LUA programming language was used for writing the simulation code. The study of the daylighting for the lightwell was based on changing four parameters and monitoring their effect on changing the illuminance of the building and hence daylighting of the lightwell. These parameters are: reflectance of the materials, width of the windows, width of the lightwell, length of the lightwell and the orientation of the whole building. Fig. 2 displays the flow chart for the used algorithm in the daylighting analysis.

The criteria which were used for the daylighting analysis are as follows:

1) Changing the reflectance of the materials from 0.3 to 0.9 in 0.1 increments.

2) Changing the width of the windows from $1000 \mathrm{~mm}$ to $2000 \mathrm{~mm}$ in $200 \mathrm{~mm}$ increment.

3) Changing the dimensions of the lightwell from $4000 \mathrm{~mm}$ to $7000 \mathrm{~mm}$ in $500 \mathrm{~mm}$ increment.

4) Changing the orientation of the whole building from 0 degrees to 180 degrees in 45 degrees increment.

The previous steps were done inside 5 nested while-loops and RADIANCE. Simulation was carried out to calculate the illuminance of each floor separately.

\section{RESULTS AND DISCUSSION}

There were three factors that were investigated affecting the illuminance of the rooms surrounding the lightwell which are: the orientation of the lightwell, the area of the lightwell, and reflectance of the walls. Figure 3 shows the effect of changing the orientation of the building on the illuminance of the lightwell in the fourth and third floors. It was found that the illuminance was maximum when the north of the model was oriented at 0 degrees and 90 degrees and it was minimum at 45 and 135 degrees respectively. Also it was found that this effect is very obvious in the fourth floor, however in the four lower floors the effect was nearly not existing.

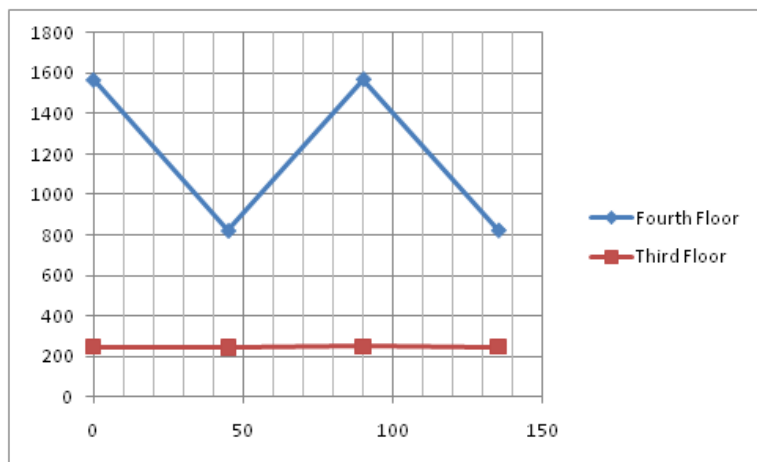

Fig. 3. A graph showing the effect of changing the orientation of the building on the luminous flux in the fourth and third floors.

The second effect which was investigated was changing the lightwell area. It was found that changing the lightwell area was slightly affecting the illuminance of the building. Fig. 4 shows the effect of changing the lightwell length on the illuminance of the building in the fourth, third and second floors when sweeping the lightwell length from 4 to 7 meters at 0.5 meters step and the lightwell width is fixed at 4 meters.

As it is clear from the graph, the luminous flux is increasing at first with increasing the area; however it is decreasing suddenly when the lightwell length is 6 meters in the fourth and third floors. The second floor shows a different behavior as the luminous flux didn't decrease when the lightwell length 
reached 6 meters. In general, changing the area had a tiny effect on changing the illuminance of the building which is not the case with the effect of the orientation of the building. The last factor which was experimented was the reflectance of the walls. It was found that increasing the reflectance of the walls in general had a major effect in increasing the illuminance of the building. The increase was huge in the fourth floor however and it was smaller in the lower floors. Figure 5 shows a graph explaining this effect in the fourth, third and second floors respectively.

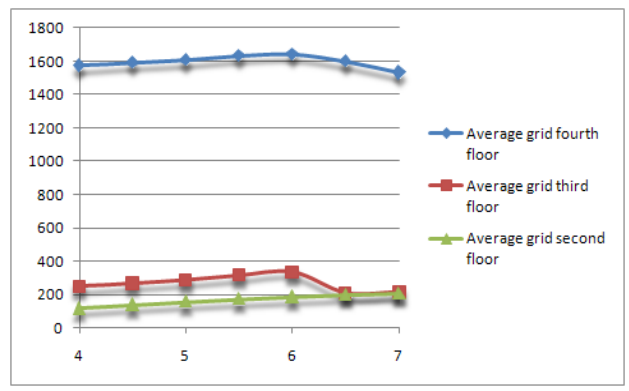

Fig. 4. A graph showing the effect of changing the area of the lightwell building on the luminous flux in the fourth, third and second floors respectively.

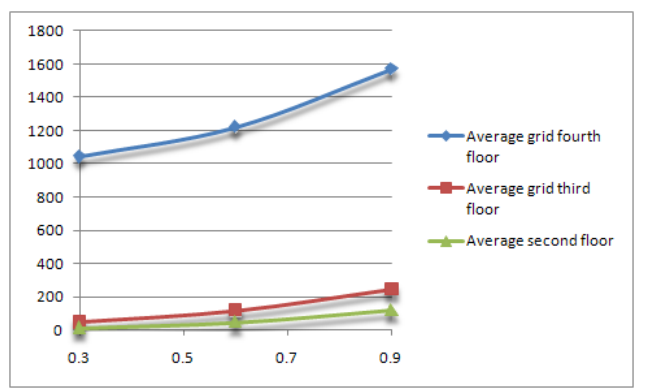

Fig. 5. A graph showing the effect of changing the reflectance of the walls on the luminous flux in the fourth, third and second floors respectively.

The following figures show images of the ISO contours of lighting measure at different levels of the building. Figs. 6, 7 and 8 show Iso Contours of the building in the ground, second, and fourth floors using RADIANCE tool.

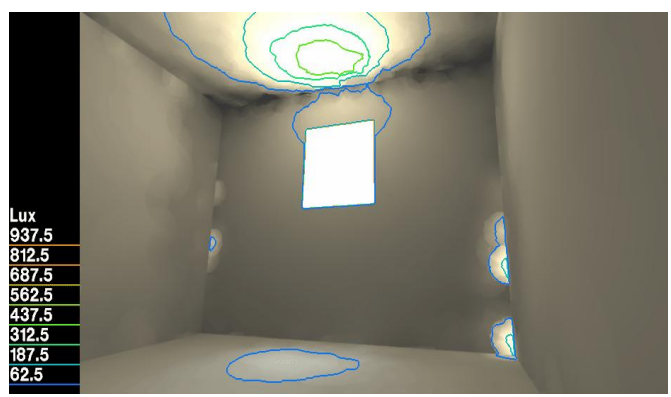

Fig. 6. Iso Contours in the ground floor

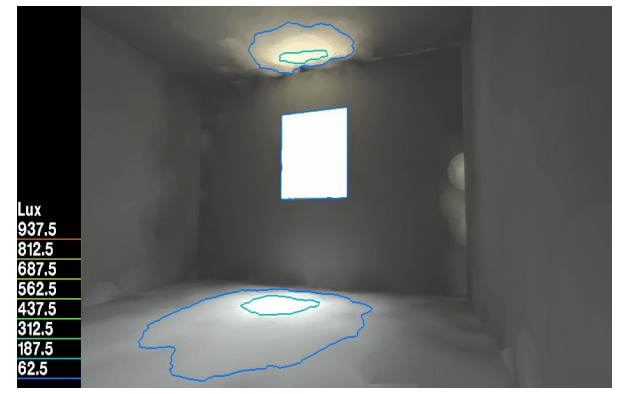

Fig. 7. Iso Contours in the second floor

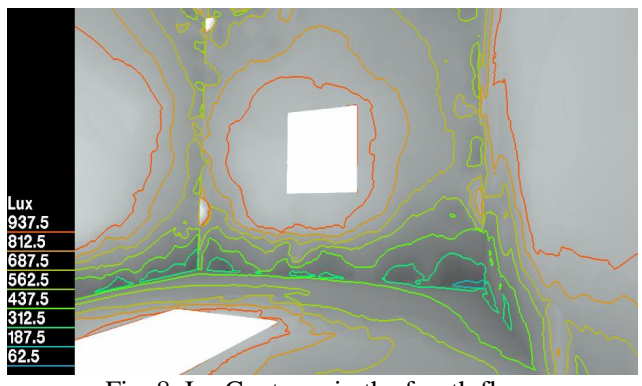

Fig. 8. Iso Contours in the fourth floor.

Figs. 9 and 10 show Iso Contours when the north of the model is oriented at 0 degrees and when it is oriented at 45 degrees respectively.

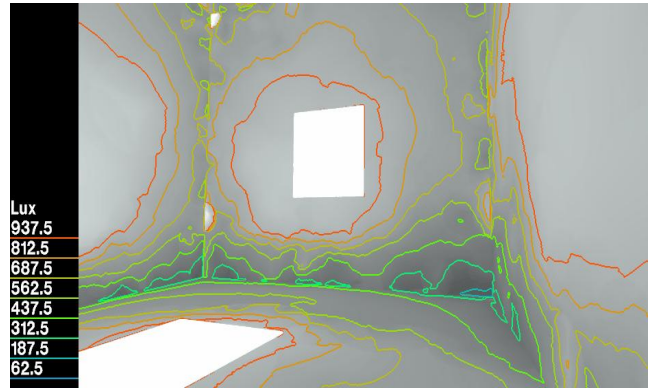

Fig. 9. Iso Contours when the north of the model is oriented at 0 degrees.

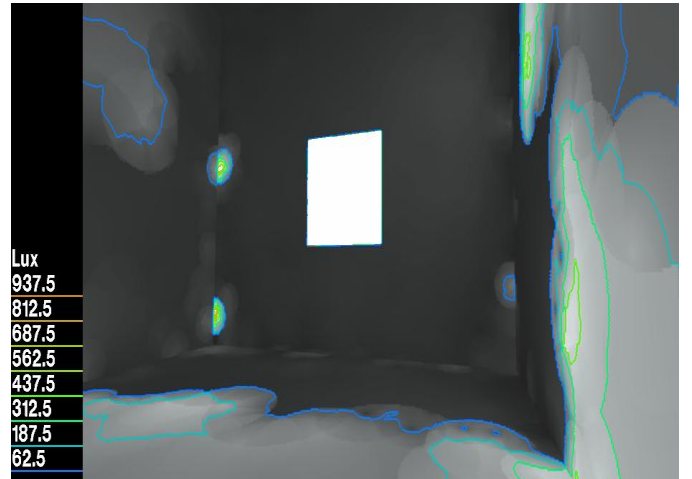

Fig. 10. Iso Contours when the north of the model is oriented at 45 degrees.

\section{CONCLUSION}

The light well allows the exploitation of daylighting by bringing natural light into areas on the inside of buildings, thus allowing daylight access to 'dead' areas of the building. The configuration of the lightwell, however, is determined based on the purpose of the interior space and the use of the building. The authors have developed insights regarding the critical daylighting performance factors by evaluating the relative effect of various light well configurations on illumination level and its distribution with different light well geometries. For these, parametric measurements of illumination level through simulations using RADIANCE have been performed. This research work will be of interest to building officials setting code requirements in Egypt and many parts of the world as well as practicing architects.

\section{REFERENCES}

[1] Egyptian Ministry of Housing, Utilities, and the Urban Development, Central Agency For Public Mobilization \& Statistics Data Cairo, Kasr El Ainy, Cairo, Egypt.

[2] M. D. Egan and V. W. Olgyay, Architectural Lighting, 2nd ed. McGraw-Hill: New York, 2002, pp. 27-30. 
[3] H. Kotani, M. Narasaki, R. Sato, and T. Yamanaka, "Environmental assessment of light well in high-rise apartment building," Building and Environment, vol. 38, no. 2, pp. 283-289, 2003.

[4] Z. Kristl and A. Krainer, "Light wells in residential building as a complementary daylight source," Solar Energy, vol. 65, no. 3, pp. 197-206, 1999.

[5] N. Lechner, Heating Cooling, Lighting, 2nd ed. Wiley: New York, 2001, pp. 368-369.

[6] Y.-H. Su et al., "Evaluation of a lightwell design for multi-storey buildings," International Journal of Energy Research, Int. J. Energy Res. (2010), Wiley Inter Science Published Online: 14, Jan 2010.

[7] I. Diego et al., "Daylight factor simulations - how close do simulation beginners 'really' get?" in Proc. Eleventh International IBPSA Confe. Glasgow, Scotland, July 27-30, 2009.

[8] J. Mardaljevic, "Simulation of annual daylighting profiles for internal illuminance," Lighting Research \& Technology, vol. 32, no. 2, pp. $111-118,2000$

[9] C. F. Reinhart and M. Andersen, "Development and validation of a Radiance model for a translucent panel," Energy and Buildings, vol. 38, no. 7, pp. 890-904, 2006.

[10] C. F. Reinhart and O. Walkenhorst, "Dynamic RADIANCE-based daylight simulations for a full-scale test office with outer venetian blinds," Energy \& Buildings, vol. 33, no. 7, pp. 683-697, 2001.

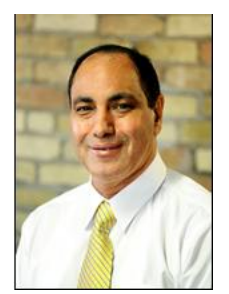

Bakr M. Aly Ahmed is an assistant professor in NDSU. He obtained the Ph.D. in Environmental Design and Planning, Virginia Tech, Virginia, USA in 2001, M. Sc. in Architecture, Minia University, Egypt in 1990, and B. Sc. in Architecture, Building Technology, Minia University, Egypt in 1984.

Dr. Bakr has 27 years of academic and teaching experience in architecture. His primary teaching courses at NDSU are: structural design, environmental control systems, high-rise design studio, and master thesis.

He worked in numerous projects: beach resorts, housing developments, and mix-use urban projects. His research interest focuses on sustainable design modeling, environmental capacity measurements, and simulation modeling for pedestrian movement in large buildings.

Dr. Bakr is a licensed member of the Syndicate of Egyptian Engineers since 1984 and an associated member of the American Institute of Architecture. Selected publications: "The Good, Bad, and Ugly" in Architectural Case Studies, DEFSA, 2007, and "Means of Egress Building Code Compliance Diagrams”, AEI, 2006.

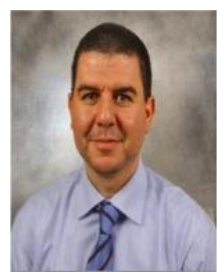

Khaled Nassar is an associate professor in AUC. He obtained the Ph.D. in Environmental Design and Planning, Virginia Tech, Virginia, USA in 2000, M. Sc. in Architecture, Cairo University, Egypt in 1995, and B. Sc. in Architecture, with honor, Cairo University, Egypt in 1984.

$\mathrm{He}$ is prior to joining AUC, he was an assistant professor of Maryland Eastern Shore, USA, as well as serving as the chair of the department of Architectural Engineering at the University of Sharjah, UAE.

Dr. Khaled research interest focuses on simulation applications, computing in design and construction, quantitative methods in construction management and technology as well as visualization. He has published over 100 refereed journal and conference papers in top journals in the field with several best paper awards and advised many Masters and Ph.D. students on topics ranging from data mining applications, to simulation of onshore wind farm construction. Furthermore he participated in research grants worth in excess of one and half million dollars with projects funded by the Illinois Department of Transportation (IDOT), Caterpillar Inc., National Science Foundation (NSF), the European Union (EU). 